\title{
Cytotoxic Effects of Kynurenic Acid and Quinaldic Acid in Hepatocellular Carcinoma (HepG2) Cell Line ${ }^{\dagger}$
}

\author{
Pınar Atalay Dündar and N. Nalan İmamoğlu * \\ Department of Basic Sciences, Faculty of Pharmacy, Erciyes University, Kayseri 38039, Turkey; \\ pdundar@erciyes.edu.tr \\ * Correspondence: nimamoglu@erciyes.edu.tr; Tel.: +90-532-565-8697 \\ + Presented at the 2nd International Conference on Natural Products for Cancer Prevention and Therapy, \\ Kayseri, Turkey, 8-11 November 2017.
}

Published: 10 November 2017

\begin{abstract}
Kynurenic acid (KYNA), tryptophan metabolite synthesized in the kynurenine pathway, is present in human body fluids as well as in variety of foods, herbal medicines and honeybee derived foodstuffs. KYNA is an endogenous antagonist of all ionotropic glutamate receptors. It has been found that glutamate antagonists inhibit proliferation of different human tumor cells. Quinaldic acid (QUINA), a derivative of KYNA, is also a tryptophan metabolite and shows high similarity to KYNA in physiological and pathological processes. It has been suggested that both of these endogenous substances have antiproliferative activities in colon cancer cell lines. In this study, the cytotoxic activities of KYNA and QUINA in human hepatocellular carcinoma (HepG2) cell line were investigated. HepG2 cells were exposed to different concentrations $(1 \mu \mathrm{M}-10 \mathrm{mM})$ of KYNA and QUINA for 24,36 and $48 \mathrm{~h}$. The cell viability was determined by MTT assay. Our results showed that KYNA and QUINA decreased the viability of HepG2cells on a dose- and time-dependent manner, and have cytotoxic effects in milimolar concentrations. To the best of our knowledge, this is the first report on cytotoxic effects of KYNA and QUINA in HepG2 cell lines. Further studies needed to explore the potential roles of KYNA and QUINA as a chemotherapeutic or chemopreventive agent in hepatocellular carcinoma.
\end{abstract}

Keywords: Kynurenic acid; Quinaldic acid; cytotoxic activity; HepG2

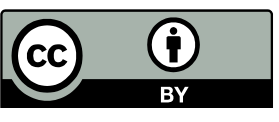

(C) 2017 by the authors. Licensee MDPI, Basel, Switzerland. This article is an open access article distributed under the terms and conditions of the Creative Commons Attribution (CC BY) license (http://creativecommons.org/licenses/by/4.0/). 